
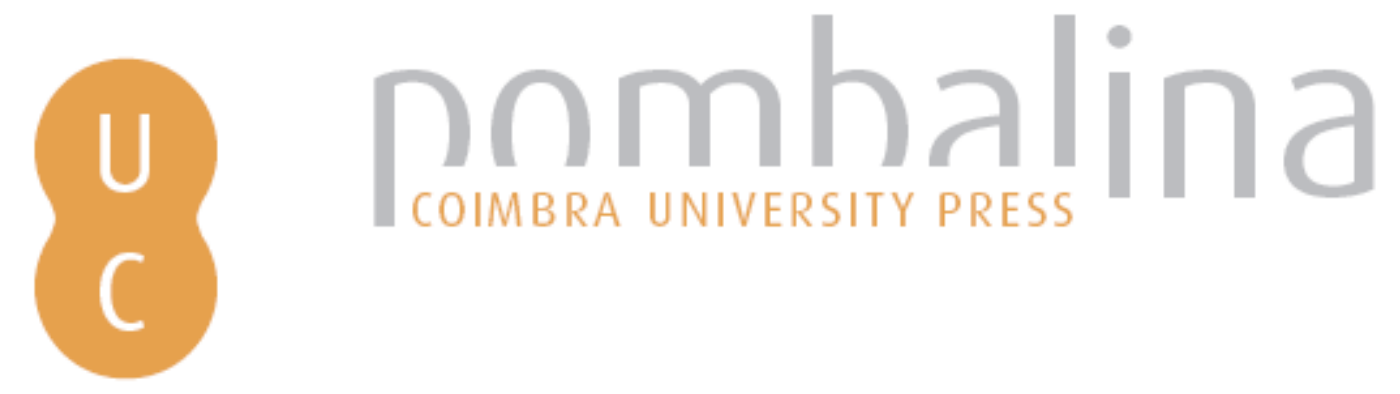

\title{
Quinze anos na Biblioteca Geral: um percurso de aprendizagem e de afetos
}

Autor(es): $\quad$ Simões, Maria da Graça

Publicado por: Imprensa da Universidade de Coimbra

URL

persistente:

URI:http://hdl.handle.net/10316.2/36997

DOI:

DOI:http://dx.doi.org/10.14195/978-989-26-1045-0_26

Accessed : $\quad$ 26-Apr-2023 13:55:02

A navegação consulta e descarregamento dos títulos inseridos nas Bibliotecas Digitais UC Digitalis, UC Pombalina e UC Impactum, pressupõem a aceitação plena e sem reservas dos Termos e Condições de Uso destas Bibliotecas Digitais, disponíveis em https://digitalis.uc.pt/pt-pt/termos.

Conforme exposto nos referidos Termos e Condições de Uso, o descarregamento de títulos de acesso restrito requer uma licença válida de autorização devendo o utilizador aceder ao(s) documento(s) a partir de um endereço de IP da instituição detentora da supramencionada licença.

Ao utilizador é apenas permitido o descarregamento para uso pessoal, pelo que o emprego do(s) título(s) descarregado(s) para outro fim, designadamente comercial, carece de autorização do respetivo autor ou editor da obra.

Na medida em que todas as obras da UC Digitalis se encontram protegidas pelo Código do Direito de Autor e Direitos Conexos e demais legislação aplicável, toda a cópia, parcial ou total, deste documento, nos casos em que é legalmente admitida, deverá conter ou fazer-se acompanhar por este aviso.

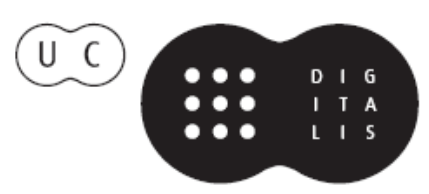



Tendo como pano de fundo as Comemorações dos seus 500 anos, a Biblioteca Geral da Universidade de Coimbra organizou um Congresso Internacional subordinado ao tema "A Biblioteca da Universidade: permanência e metamorfoses", que teve lugar nos dias 16, 17 e 18 de janeiro de 2014, no auditório da Reitoria da Universidade de Coimbra.

O objetivo maior desta reunião científica foi o de refletir sobre o presente e o futuro das bibliotecas que servem públicos universitários. Numa outra vertente, procurou chamar-se a atenção para a importância de que a Biblioteca se reveste, tendo em vista o progresso do conhecimento técnico e científico. Por último, o Congresso pretendeu instituir-se como oportunidade de reflexão prospetiva e como lugar de encontro entre as sensibilidades de todos os que trabalham profissionalmente com livros e com outros suportes de natureza bibliográfica.

Nesse sentido, foram apresentadas Conferências, Mesas Redondas e sessões de Testemunhos em torno de temas como o valor das bibliotecas universitárias, a biblioteca universitária em contexto; as mudanças e os desafios; a biblioteca universitária e a sociedade da informação e conhecimento; o impacto do acesso aberto na comunidade científica, e as bibliotecas digitais. 
MARIA DA GRAÇA SIMÕES

Universidade de Coimbra

\section{QUINZE ANOS NA BIBLIOTECA GERAL: \\ UM PERCURSO DE APRENDIZAGEM E DE AFETOS}

Quando o Senhor Diretor da Biblioteca Geral, Prof. Doutor José Augusto Cardoso Bernardes, me convidou para participar no Congresso - A Biblioteca da Universidade: permanência e metamorfoses, relativo aos seus quinhentos anos de existência, senti-me especialmente honrada, pelas razões óbvias e comuns a todos aqueles que, tal como eu, tiveram o privilégio de serem convidados para este evento, mas em particular, pelo facto de ter sido nesta Casa Maior da Cultura e do Saber, que tive a imensa sorte de ter iniciado a minha carreira profissional, mesmo antes de ter terminado o meu Curso no tempo, como bolseira. Foi aqui, onde também comecei a dar os primeiros passos, embora, de forma ingénua e inconsciente na minha carreira científica, que iria culminar no Doutoramento. Pelas razões aduzidas sinto-me "imensamente impelida" a registar o meu breve testemunho, porém, intenso, no que concerne à aprendizagem e sobretudo aos afetos que, naturalmente, fui construindo nesta Casa e que hoje, tal como ontem, me ligam de uma forma singular a ela.

Em 1991, entrei na Biblioteca Geral a convite da Dra. Teresa Pinto Mendes, à época, figura ímpar na área da Biblioteconomia, e minha Professora no Curso de Especialização de Ciências Documentais da Faculdade de Letras, que muito me orientou e sensibilizou para as problemáticas de natureza teórica e metodológicas, em especial no que concerne à representação da informação por assunto. De tal modo que esta matéria viria a constituir-se como principal objeto de estudo da minha tese de Doutoramento, tema, que de resto, ainda hoje representa a primeira linha da minha investigação. 
Confesso, que tal convite, na altura, me aterrou. Aterrou-me, porque a Biblioteca Geral da Universidade de Coimbra, na época, virgem relativamente às novas tecnologias da informação e da comunicação, reunia na Sala do Catálogo, na Sala de Leitura e nas Boxes, os nomes dos académicos mais relevantes, essencialmente, no que se refere à Faculdade de Letras e à Faculdade de Direito, que aí desenvolviam as suas investigações e que, de algum modo nos impunham respeito. O silêncio sepulcral, que se "ouvia" depois de se passar a porta do Catálogo, que nada ou pouco tinha a ver com o ambiente jovial que eu vivia, como aluna da Faculdade de Letras, nas Bibliotecas dos extintos Institutos, onde costumava estudar, constituía-se também um elemento intimidador que era necessário considerar, na minha decisão. Os ricos fundos que abrigava, mas que para nós, estudantes de Licenciatura, inexperientes na arte da investigação, se constituíam acervos de pouca serventia, sendo apenas, de quando em vez, usados para engordar a lista de referências bibliográficas, de algum trabalho de final de Curso, ou para lhes dar um aspeto mais erudito. O facto de a maioria dos funcionários serem seniores e de semblante circunspecto concorria, também, para nos sentirmos pouco à vontade. Acrescia o facto de a Biblioteca Geral possuir um excelente corpo de bibliotecários, com quem, a posteriori, aprendi com o saber e, em especial, com a sua sabedoria, desde os conhecimentos mais básicos aos mais complexos do percurso biblioteconómico, muitos dos quais, devo dizer, nunca encontrei nos livros técnicos que fui lendo ao longo da minha trajetória profissional. Os maiores especialistas e corpus desta área do conhecimento (Catalogação e Indexação) eram funcionários desta Biblioteca e também Professores destas matérias no Curso de Especialização em Ciências Documentais. Sobre eles, atrevo-me mesmo a dizer que, à época, seriam os melhores do país, e que por essa circunstância, impunham respeito técnico aos demais Colegas.

Por último, e tal qual, uma cereja no topo do bolo encontrava-se o Senhor Diretor da Biblioteca, que era tão conhecido, entre os seus pares, tanto pela sua reputação científica, como pelo seu temperamento particular, característica que nunca influenciou a minha franca e jovial relação com ele. Assim, devo dizer que ao longo da minha permanência nesta 
instituição, mantive, com ele, as mais gratificantes relações pessoais, quer na qualidade de amiga quer pelo facto de ter confiado sempre em mim enquanto técnica desta Casa.

Após um largo período de ponderação, no qual as resistências eram uma constante, aceitei o convite, porém, com uma ideia fixa na cabeça - a data do terminus do contrato.

Esperava-me, como primeiro trabalho, um conjunto de miscelâneas da Biblioteca Joanina, que se encontravam no $1^{\circ}$ piso do Salão nobre desta Biblioteca. Competia-me, nesta empresa, o levantamento das obras e o seu tratamento técnico, sob a orientação de uma Colega mais experiente. Desta tarefa, recordo-me, da árdua empreitada que era a identificação da autoria e a determinação da rubrica uniforme de algumas destas obras, muitas das quais aparentemente anónimas ou de autoria expressa de forma imprecisa. Era um verdadeiro trabalho de investigação, quase comparado à descoberta da caixa negra de um avião. A concretização deste processo passava, entre outras etapas técnicas, pela consulta no Catálogo interno da Sala do Catálogo, à qual se somavam aquelas que fazia aos Catálogos impressos, especialmente, ao Catálogo da Biblioteca Nacional de Paris, vulgo Catálogo de Paris, localizado na Secção de Manuscritos e ao Dicionário Bibliográfico Português de Inocêncio Francisco da Silva, constituído por 24 tomos, do qual conhecia, à força de tanto uso, o seu índice, como as palmas das minhas mãos. Neste, geralmente, localizava os autores cuja autoria aparecia expressa de forma imprecisa, muitas das vezes apenas com duas ou três iniciais, como se de um código se tratasse. Após uma análise mais pormenorizada, concluí que tal facto se encontrava associado à circunstância de alguns destes textos terem sido concebidos na conturbada época das Revoluções liberais. Resolver estas autorias era como decifrar um enigma, o que me deixava, confesso e, perdoe-se a parca modéstia, inchada como um peru nas vésperas de Natal... Ainda, no que concerne ao tratamento técnico de tais raridades, a determinação do assunto, para atribuição da respetiva classificação, era para mim uma aventura, pois descobria com o assombro, que é comum a quem se depara com o desconhecido, temas que eram, para mim, absoluta novidade. Assim, nestas miscelâneas, e pela mão de Brotero 
e outros estudiosos entrei no mundo da Botânica, pois a maioria destes pequenos textos, encadernados de forma avulsa, de acordo com os caprichos do encadernador, versavam matérias sobre o Jardim Botânico da Universidade, alguns dos quais em latim. O contacto com as classes, com as espécies e com as subespécies de plantas em que, entre outros naturalistas, Lineu e Buffon categorizaram o Reino vegetal, era para mim um momento muito especial. A designação científica destas espécies, que eu, como leiga, apenas conhecia, pela sua nomenclatura vernácula, constituía um grande foco de interesse. Desta classificação taxonómica ficar-me-ia gravada na memória a espécie das Rosáceas, (da qual fazem parte as rosas) que eram primas, em grau indeterminado, das Dicotiledóneas. As pequenas peças de teatro, cuja maioria era de teatro de cordel, também mereciam a minha atenção, pois sempre retratavam situações assaz rocambolescas. Outros textos havia, porém, que pouca atenção me solicitavam, aos quais, por este facto, aplicava de forma implacável, as técnicas de análise documental: eram lidos na diagonal, pois o propósito era apenas identificar o assunto principal com a segurança conceptual possível, para lhes poder atribuir uma classificação idónea.

Mas nem tudo era árduo, no tratamento destas obras. A oportunidade que tinha em as levantar na Biblioteca Joanina, constituía, para mim, um dos momentos mais gratificantes e por isso o mais aguardado deste meu primeiro ano de trabalho na Biblioteca Geral, de tal modo que não posso deixar de o descrever.

Chegada à Biblioteca Joanina, depois de me conseguir infiltrar, através da orla de turistas nipónicos, que aguardavam a visita a esta Biblioteca, tocava à campainha três vezes, sistema que era usado por todos os funcionários da Biblioteca, (nunca soube se a escolha deste código se teria baseado na novela de James M. Cain: O carteiro toca sempre duas vezes). Atendia um funcionário muito gracioso nos comentários que fazia relativamente à Biblioteca Joanina e aos turistas. Aberta a porta, passava à frente destes, que ficavam perplexos e um pouco irritados com este meu comportamento abusivo, mas que rapidamente suavizavam quando este funcionário repetia automaticamente, sucessivamente e em tom firme: The boss; the boss, the boss... E logo, ainda eu não me tinha recomposto 
desta cena hilariante, e já ele apontava com o indicador em riste para o Magnânimo, e repetia, em inglês ou em francês, conforme a nacionalidade dos turistas: Eh voilá! Jean Cinquiéme ou Is John de Five... comportamento, ao qual o Real retratado assistia impávido e com um olhar seráfico à alternância idiomática, do seu nome, cujo critério se baseava, tão só, na nacionalidade de quem o visitava.

Foi neste ambiente que passei o meu primeiro ano na Biblioteca Geral, ao fim do qual vi o meu contrato renovado. O segundo e os anos seguintes foram decisivos na minha vida profissional. As dúvidas que tinha em abraçar esta profissão e a resistência inicial que tinha em trabalhar nesta Casa começaram a dissipar-se. Para este volte-face contribuíram as novas responsabilidades que assumi, mesmo na qualidade de bolseira e, sobretudo as amizades que se começaram a afirmar com os meus novos/as Colegas, a maioria das quais se mantêm até hoje de forma muito estreita.

A entrada no segundo ano coincidiu com a conclusão da minha Pós-graduação em Estudos Europeus na Faculdade de Direito desta Universidade. Esta circunstância concorreu para o facto de me ter sido atribuída a coordenação técnica das obras que recebíamos a título de depósito (gratuito) das Organizações Internacionais (ONU, GATT/OMC, AEN, UNICEF, PNUD, OCDE ...). Foi um período muito intenso e de grande aprendizagem talvez o maior pelo qual passei nesta Biblioteca e ao longo da minha vida profissional. A par desta aprendizagem técnica, não posso deixar de manifestar o conhecimento que fui assimilando relativamente às matérias abordadas que, se caracterizavam, por um lado, por reunirem pouco consenso e, por outro, pela sua contemporaneidade. O facto de ter trabalhado com estas matérias, abriu-me o mundo para outra leitura, bem diferente daquela que eu tinha dele até então. A aprendizagem técnica, que desenvolvi durante todo este tempo veio a culminar, passados três anos, num convite para substituir a professora da cadeira de Catalogação no Curso de Especialização em Ciências Documentais. A entrada para a vida académica, embora, em regime parcial, fez-me encarar a profissão de uma outra forma, agora muito mais consciente e responsável. A aplicação da técnica pela técnica e limitar-me à consulta de manuais de referência e catálogos, tornou-se insuficiente. Havia que contextua- 
lizar e conceptualizar essa técnica, de a enquadrar em moldes teóricos, conferir-lhe substância. Para tal, urgia que fizesse leituras refletidas, de modo a encontrar os fundamentos, os princípios e o porquê da aplicação de uma determinada técnica. Neste percurso de concetualização, comecei a privar com os autores que faziam parte do espólio do Gabinete do Dr. Jorge Peixoto. Assim, estes anónimos começaram, discretamente, a povoar e a perturbar o meu espírito, que até aqui era pacífico e intelectualmente frugal, pois saciava-se apenas com a prática. A consolidar esta nova atitude profissional, concorreu o facto de em finais de 90, ter sido convidada para substituir a minha antiga Professora de Indexação, agora, e nesta Biblioteca, minha Colega Dra. Maria Teresa Pinto Mendes. Esta Colega e grande Amiga foi, sem dúvida, o motor que impulsionou a partir de então, a minha vida profissional e académica. Sob a sua orientação não só assumi novas responsabilidades na Biblioteca Geral, como também consolidei a nova atitude face ao estudo - tal como o provérbio chinês, também comecei a empreender que a prática, tinha a mesma utilidade do que um pente para os carecas. Face a esta nova atitude, comecei, de modo sistemático, a aprofundar os meus estudos teóricos e metodológicos, que iriam concorrer a curto prazo, para o Mestrado e mais tarde para o Doutoramento nesta área. Nesta nova etapa, em colaboração com uma Colega e, naturalmente de acordo com as diretivas metodológicas e técnicas da Dra. Teresa Pinto Mendes, reorganizei a Sala de Leitura, arrumação que, de resto, ainda hoje se mantém. As obras até então, com um sistema de cota no qual era registado (Piso, sala, estante e número sequencial que ocupavam na estante) passavam agora a ter uma cota classificada, isto é: a cota traduzia o assunto que versava essa obra, conferindo deste modo jus ao livre acesso, sistema de arranjo próprio de uma biblioteca universitária. Foi um trabalho árduo e contínuo, no qual tivemos de ultrapassar algumas resistências. Nesta tarefa a fase preliminar, foi, para mim, a mais interessante, pois a sua conceção obrigava-me a ter reuniões semanais com esta minha antiga Professora, cujo propósito consistia em adequar as potencialidades do Sistema de classificação, (CDU) ao acervo e às necessidades reais e potenciais do utilizador. Neste período desenvolvi, sobremaneira, as minhas compe- 
tências cognitivas e técnicas. Foi, sobretudo com esta experiência, que comecei a considerar na Biblioteca Geral como uma Escola, na qual não só aprendia prática, mas também aprendia a apreciar o valor da teoria e das abordagens metodológicas como meios estratégicos de resolver novas situações.

Era prática da Casa intercalar os novos projetos com outros trabalhos de rotina. Neste sentido, não posso deixar de referir, talvez a maior de todos e o mais esperado e que, para mim, constituía um bálsamo cultural - A indexação do Depósito Legal. O dia da chegada do Depósito Legal à Secção de Catalogação, apesar de ter uma periodicidade mensal, era sempre singular, tanto pela azáfama que trazia a todos os funcionários envolvidos neste processo, como também pelas novidades que aportava. Todos nós gostávamos de "coscuvilhar" as novidades editoriais, mesmo quando já não eram, assim tão "novidade” como seria desejável! Nos últimos anos que passei na Biblioteca Geral, o seu atraso era já considerável relativamente ao período expectável, circunstância que, para os mais atentos, já se evidenciava como um dos muitos indicadores da crise nacional! A este mau presságio económico-financeiro, acrescia outro muito similar, cuja escala era muito maior, e que por isso mesmo, denunciava uma outra crise, esta a nível internacional: estou a falar do decréscimo do número de obras que eram oferecidas pelas agências internacionais, muitas das quais, passariam num ápice da modalidade de oferta a aquisição. Quando ocorreu esta situação, fiquei profundamente confrangida, pois deixei de trabalhar com os livros da OCDE, através dos quais tinha apreendido tantos conceitos e tantas ideias que até aí supunha serem reféns de determinados profissionais, tais como economistas, gestores e outros profissionais afins. Neste sentido, os conhecimentos que aprendi destes textos, foram responsáveis, para bem e para mal, no entendimento mais lúcido e real que comecei a ter do mundo. Os meandros da política e da economia internacional, antes tão obscuros tornavam-se agora transparentes. Através da análise destes textos e, sobretudo, da observação atenta das estatísticas que, quase todos continham, comecei a empreender, no meu espírito, de uma forma muito clara que, efetivamente, tal como acontece com as pessoas, também existiam países mais livres e 
mais iguais do que outros. Foi nesta circunstância que a hipocrisia, que até aqui considerava no abstrato, começou a ganhar rosto.

Do mesmo modo que se desenvolviam e fortaleciam os meus conhecimentos técnicos e científicos, também os afetos se tornavam cada vez mais estreitos com as pessoas com quem privava. Para muito contribuíram as discussões profissionais com os/as Colegas, a maioria, agora amigos/as. Havia, contudo um Serviço que a Biblioteca Geral prestava e continua a prestar à comunidade académica que, de uma forma geral, nos aproximava de uma maneira muito singular, no que concerne aos afetos: era o Serviço noturno. As pessoas que faziam este Serviço, na maioria dos casos, trabalhavam 12 horas, por dia, no dia em que lhes competia fazê-lo. Todo este esforço concorria, naturalmente, para uma certa vulnerabilidade, que se por um lado convergia, em alguns casos, para situações menos agradáveis, por outro, e na sua maioria, conduzia à partilha de afetos. Foi neste contexto, mais intimista do que profissional, que estreitei relações profissionais e onde fiz as amizades que ainda hoje perduram. Para ilustrar a particularidade deste ambiente, lembro apenas que, no final de cada período escolar, havia sempre um jantar, que era realizado por cada turno. Lembro-me, em especial, de um deles que era confecionado por um funcionário já sénior. Nesse dia, a partir das onze da manhã já o cheiro que se fazia sentir nos depósitos, denunciava a tão célebre iguaria: os ossos com orégãos do Senhor Simões, aos quais nenhuma dieta resistia... Imperdíveis! Tantos e tantos outros momentos de convívio se seguiam a este, cujo denominador comum era uma solidariedade gratuita e um carinho incomensurável.

$\mathrm{Na}$ qualidade de permanente aluna desta Casa, referência primeira da Universidade de Coimbra, quero expressar o meu profundo agradecimento, a título póstumo, a uma Colega com quem nunca trabalhei mas que deixou, contudo, uma marca indelével na minha formação, de modo que, ainda hoje, continuo a considerar muitíssimo os seus reparos. Refiro-me à Dra. Maria Luísa Lemos, Bibliotecária erudita, que tinha sido responsável pela Secção dos Manuscritos, e que, à minha chegada à Biblioteca, exercia a função de Responsável pela Secção das Músicas. Com a generosidade que é própria dos Grandes, soube partilhar comigo o seu 
sentido de rigor metodológico, a sua permanente inquietude científica, a sua cultura humanista e, sobretudo, a sua imensa humildade intelectual.

Para a maioria dos funcionários, esta Senhora era uma figura anacrónica, talvez uma personagem extraída de um filme de época, no caso concreto uma Bibliotecária do início do século XX. Na verdade, assim não era! Era uma pessoa que estava muito para além do seu tempo! A primeira vez que assinei um manifesto ecologista fi-lo pela iniciativa da Dra. Maria Luísa, que se insurgiu, por esta via, contra o derrube de uma árvore secular, na Praça da República desta cidade. Porém, e em abono da verdade, o seu aspeto físico e a sua rotina diária contribuíam em muito para essa falsa ideia. De extrema magreza, a tanger o estado de anorexia, de tez muito pálida (fosse de Inverno ou de Verão) e com uma saia, invariavelmente até aos tornozelos, chegava às oito horas da manhã. Depois de tomar um café duplo no Bar das Letras, dirigia-se à Biblioteca, de onde apenas voltaria a sair por volta das oito da noite, e muitas vezes pelas 11 horas. Tinha por hábito, pela estima que votava à investigação e a quem a ela se dedicava, abdicar do mês de Agosto de férias, para atender os investigadores estrangeiros. Nesta circunstância, muitas vezes a Dra. Luísa Lemos dizia: - Amanhã tenho de receber um PH.D. Era com esta familiaridade académica que se referia aos investigadores estrangeiros que aproveitavam as férias para se deslocarem ao nosso país, em particular à Secção dos Manuscritos, com o fim de desenvolverem os seus estudos e que ela tanto apoiava nas suas pesquisas, não sendo raras as vezes que, a expensas suas, lhes enviava para os seus países, o material que ficava a fotocopiar.

Pronunciava-se sobre as coisas simples da vida com a mesma ênfase com a qual se pronunciava sobre as de elevado valor, situação que indicia por si, o quanto a Dra. Maria Luísa Lemos considerava a relatividade das coisas. O seu discurso, erudito muitas vezes mesclado de figuras de estilo, onde as metáforas predominavam, era, por vezes, para nós, os mais novos, semanticamente obscuro, porque não a conseguíamos entender.

Por forças da investigação, dirigia-se muito à Seção onde eu trabalhava, sendo rara a vez, nessas idas e vindas, em que não se esquecia de algo, sobre os velhos Catálogos internos. Foi devido a esta sua característica que 
vivi um dos momentos mais hilariantes da minha permanência nesta casa. Uma vez, numa noite de inverno, marcada por uma tempestade medonha, encontrando-me sozinha a fazer serviço noturno, entrou a Dra. Maria Luísa, a procurar de forma exaurida o Bomtempo. Eu, absorta, em outras realidades mais contemporâneas e práticas, talvez a indexar um livro da OCDE, não entendia, porque me perguntava se eu tinha visto algures o Bomtempo, quando lá fora caía uma enorme tormenta... Fiquei tão perplexa que não consegui oferecer-lhe ajuda. Após uma busca incessante aos locais mais recônditos da Seção, surgiu com um ar radioso e com uma tese de Doutoramento nas mãos, que era sobre o nosso compositor João Domingos Bomtempo, tese que mais uma vez tinha olvidado em cima de um Catálogo de Autores e Títulos...

Demorei, também, algum tempo a identificar uma obra, que amiúde a Dra. Maria Luísa, consultava nesta Secção e, que muito naturalmente, como se do título original da obra se tratasse, denominava: Bíblia dos burros. Era a Enciclopédia Luso-brasileira. Não que tivesse nada contra esta obra em particular, apenas não entendia como ela se constituía a base de estudo para a elaboração de muitos trabalhos académicos, por parte dos alunos!

É a esta permanente memória, povoada, sobretudo, por afetos, que recorro hoje para entender as metamorfoses próprias da vida, e que por ser tão especial para mim, entendi partilhar. 
José Augusto Cardoso Bernardes é Professor da Faculdade de Letras da Universidade de Coimbra e Diretor da Biblioteca Geral da Universidade

Ana Maria Eva Miguéis é coordenadora do Serviço Integrado das Bibliotecas da Universidade de Coimbra

Carla Ferreira é bibliotecária nos Serviços de Biblioteca e Documentação da Faculdade de Letras da Universidade de Coimbra. 


\section{Série Documentos}

Imprensa da Universidade de Coimbra

Coimbra University Press

2015

C •

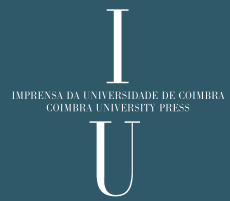

